https://doi.org/10.36909/jer.v9iICRIE.11635

\title{
Factorial Design for Studying the Properties of Recycled Aggregate Concrete Exposed to Aggressive Media
}

\author{
Ammar Ali Abed* and Ibtisam Mustafa Kamal * \\ *General Company for Ports of Iraq, Department of Engineering Affairs, Basrah, Iraq \\ *Iraq University College, Civil Engineering Department, Basrah, Iraq \\ ${ }^{* *}$ Civil Engineering Department, Faculty of Engineering, Soran University, Kurdistan Region- \\ Iraq \\ **Email: ibtisam.kamal@soran.edu.iq; Corresponding Author.
}

\begin{abstract}
Recycled Aggregate Concrete (RAC) mixes (1.15: 2.3: 4.6) cement: fine aggregate (sand): coarse aggregate (demolition concrete waste), water / cement (0.5), and $50 \%$ demolition aggregates were prepared according to standard procedure. The resistance of the recycled aggregate concretes towards chemicals was investigated throughout the attack of (Acid: acetic Acid HAC, and salt: Sodium Chloride $\mathrm{NaCl}$ ) solutions. The test was carried out based on adopted experiments designed using Response Surface Methodology (RSM). A 2operating parameter central composite design was adopted to study the impact of concentration of the $\mathrm{HAC}$ and $\mathrm{NaCl}$ solutions (0.1-0.45) Molar, and immersion period (0.576.9) day of the (RACs) specimens on weight loss, compressive strength and density. The results obtained confirmed that weight loss increases, but both compressive strength and density decreases after the aggressive solutions attack, however HAC seemed more aggressive. The decrease in compressive strength was (2.8-42) \% and (3.2-10.8) \%, while the decrease in density was $(0.72-2.05) \%$ and $(0.6-1.8) \%$ for the samples immersed in HAC and $\mathrm{NaCl}$ solutions respectively. The mathematical models presenting the effect of concentration of the aggressive media and immersion duration on weight loss, compressive strength and
\end{abstract}


density were estimated, and the effects were optimized and modeled. The Analysis of Variance (ANOVA) revealed that an optimum compressive strength (37.8 and 34.8) MPa is obtained for the RACs immersed for 0.56 day at 0.1 Molar $\mathrm{HAC}$ and $\mathrm{NaCl}$ respectively.

Key words: Recycled Aggregate Concrete; Chemical Resistance; Aggressive Solutions; Response Surface Methodology; Optimization; Modeling.

\section{INTRODUCTION}

Globally, concrete is the ultimate used manufactured construction material due to its reasonable price and advantageous properties, however, the construction industry accounts for intensive energy consumption and natural resources (Nochaiya et al., 2010; Malesev et al., 2014). Among the key environmental concerns facing cement industry are the greenhouse gas emissions which has a considerable effect on the environment, and the depletion of natural raw materials; the aggregate materials of good quality, in addition to production of huge amount of industrial waste and demolished construction waste which impart to about half of the world's solid waste.

The waste materials play vital role in contamination the environment because of the restricted accessibility of landfills for disposing of the waste. Accordingly, different sustainable applications of demolition waste from construction industries were adopted using the (re-use, recycle and recovery) concept (Ghaffar et al., 2017; Omotayo et al., 2019). The reuse of demolition waste as fine and coarse recycled aggregate (RA) in concrete became of global concern and great interest for stakeholders from the construction industry and researchers from academic institutes interested in prospective development of sustainable concrete materials and protection the environment (Shi et al., 2011; Kamal et al., 2017). The recycled aggregates are presently used in different structures and building applications include paving, filling and bridges (Li et al., 2017; Rodríguez et al., 2020).

Furthermore, it has been pointed out that concrete has suitable uses in extreme natural circumstances or in very harsh surroundings such as biogas factories, sewer, sewage farm, and cooling towers. However, the aggressive surroundings could start the corrosion of 
concrete.

Nevertheless, mitigation of chemical attack could be achieved by choosing the appropriate concrete composition to make it less penetrable, or detaching it from sever environmental conditions by using an adequate cover, or by modifying the environment to make it less harmful. Even so, it is essential to realize the mechanism of penetration of the aggressive materials into concrete and the operating variables affect it for the purpose of concrete protection from deterioration. The alkaline nature of concrete makes it susceptible to acid attack. Acids attack on cured concrete lead to formation of calcium salts as a result of conversion of calcium compounds in concrete. It has been figured out that the concentration of the acid and temperature govern the seriousness of concrete damage (Poulsen, 2005) such as the acid attack will be observed if $\mathrm{pH}$ value is $<6.5$ and hard aggression will be noticed if pH reading is < 4.5 (Tang, 1996; Neville, 2011).

Furthermore, for reinforced concrete structures like bridges and marine constructions, chloride penetration is considered as one of the major environmental attack factors which cause the corrosion of concrete reinforcement followed by the collapse of the concrete structure, which may have resulted in the need of earlier repair or renewing the structure. The use of relatively impenetrable concrete is a common method used to protect concrete and the reinforcement bars from chloride ions penetration. Therefore, for structure design and quality control purposes, it is fundamental to recognize the capability of penetration of chloride ions into concrete. In connection, there are essentially four modes of chloride ion transport through concrete, the main modes are capillary absorption, diffusion, wicking (evaporative transport), and permeation (Varghes, 2010; Liang et al., 2013; Shi and Mo, 2008).

Consequently, the first barrier in opposition to chemical incursion is to use concrete of outstanding quality and superior resistance against chemicals. This can be boosted by improving the chemical resistance of concrete and applying protective treatments for concrete exposed to severe environments. Different technologies are used to make concrete less permeable and more durable; these include using admixtures (Attiogbe and Rizkalla, 1988), nanomaterials (Wu et al., 2019; Brendt, 2001; Bertron et al., 2004; Bertron et al., 
2005) and incorporation the concrete mix with pozzolanic additives (Mehta and Monteiro, 2006; Hirao et al., 2005; Dembovskaa et al., 2017).

There has not been much research on modeling and optimization the chemical resistance of recycled aggregate concrete (RAC). The objective of the current work is to study the chemical resistance of recycled aggregate concrete samples contain $50 \%$ weight demolition concrete as coarse aggregate. Acetic acid (HAC) and Sodium Chloride ( $\mathrm{NaCl})$ solutions were selected as the attack media. The effect of the media concentration and the immersion duration of the recycled aggregate concrete samples on weight loss, compressive strength and density were investigated throughout 10 experiments designed by statistical software based on Response Surface Methodology (RSM). The studied properties were optimized, and the mathematical models explain the impact of the investigated parameters on concrete properties was estimated.

\section{EPERIMENTAL PART}

\section{MATERIALS}

The natural aggregates and Ordinary Portland cement used were bought from the municipal market in Basrah city. Demolished aggregates were prepared by grinding demolished concrete blocks collected from landfill sites in Basrah city. The demolition concrete was crushed and sieved. The aggregate particles have similar grading of natural aggregates with grading (4.7520) $\mathrm{mm}$ were used as coarse aggregates. Tap water was used for preparation the concrete pastes. The chemical composition of the used cement and the characteristics of fine aggregate (sand) conform to the Iraqi Specifications (IQS No.5/1984) and (IQ.S. No 45) respectively are listed in Table 1. 
Table 1. Characteristics of the cement and fine aggregate used

\begin{tabular}{|c|c|c|c|c|c|}
\hline \multicolumn{2}{|c|}{ Cement Specifications } & \multicolumn{2}{|c|}{ Fine aggregate sieve analys is } & \multicolumn{2}{|c|}{ Fine aggregate characteristics } \\
\hline Composition & Specifications & Sieve No. $(\mathrm{mm})$ & \% passing wt.(\%) & & \\
\hline $\mathrm{SiO}_{2}$ & $20-21 \%$ & 9.5 & 100 & Specific Gravity & 2.91 \\
\hline $\mathrm{Al}_{2} \mathrm{O}_{3}$ & $3.90-4.20 \%$ & 4.75 & 99.2 & $\mathrm{SO}_{3} \%$ & 0.48 \\
\hline $\mathrm{Fe}_{2} \mathrm{O}_{3}$ & $4.80-5.1 \%$ & 2.36 & 91.6 & Absorption\% & 0.0221 \\
\hline $\mathrm{CaO}$ & $62.50-63.50 \%$ & 1.18 & 71.6 & $\mathrm{Cl} \%$ & 0.05 \\
\hline $\mathrm{MgO}$ & $5.00 \% \operatorname{Max}$ & 0.6 & 57.3 & & \\
\hline $\mathrm{SO}_{3}$ & $2.50 \% \operatorname{Max}$ & 0.3 & 13.6 & & \\
\hline LSF & 0.66 to $1.02 \%$ & & & & \\
\hline $\mathrm{C}_{3} \mathrm{~S}$ & $55-66 \%$ & & & & \\
\hline $\mathrm{C}_{3} \mathrm{~A}$ & $3.50 \%$ & & & & \\
\hline
\end{tabular}

\section{METHODOLOGY}

In modeling and optimization, the industrial processes, Response Surface Methodology (RSM) is excessively put in application, however it has potent use in the research fields including construction to envisage the results when they role controlled operating variables (Cihan et al., 2013; Revathi et al., 2018). The mathematical and statistical operations of RSM is employed to emphasize the interaction between the independent operating variables and one or more response variables at the same time. By using the RSM software, series of experiments could be designed, each experiment has specific values of the independent (operating) variables; concentration of the aggressive solutions and duration of attack. The experiments are then run practically at the laboratory (for example in the current work chemical resistance of the RACs is tested) and the results (Responses) including \% wt. loss, compressive strength and density of the tested specimens are evaluated. The results then analyzed by the software to optimize and modeling the effect of the concentration of the aggressive solutions and duration of attack on recycled aggregate concrete properties The 
mathematical models of second order response surface with the best fittings is estimated. The software portable statgraphics centurion 15.2.11.0.exe was used in the present work.

The model is defined by the empirical equation displayed in equation 1 .

$$
Y=\beta_{0}+\beta_{1} \chi_{1}+\beta_{2} \chi_{2}+\beta_{11} \chi_{1}^{2}+\beta_{22} \chi_{2}^{2}+\beta_{12} \chi_{1} \chi_{2}
$$

Where: Y: is the response or dependent variable; $\chi_{1}$ and $\chi_{2}$ are the independent variables; and, $\beta_{0}, \beta_{1}, \beta_{2}, \beta_{11}, \beta_{22}$, and $\beta_{12}$ are the regression coefficients.

The significant differences between the effects of the independent variables $(p<0.05)$ is determined by the analyses of variance (ANOVA). The intensity of the effect of the independent variables on each considered response is identified by Pareto chart. The effects that are statistically significant at $95 \%$ as confidence level is recognized by the vertical line across the effect (significant front) in Pareto chart. The dependent parameter (responses) behaviors as a function of the independent variables are illustrated in the main trends and 3D surface response and other charts. The optimum responses are determined and the empirical regression model identify mathematically the effect of the independent variables on responses is established.

\section{PREPARATION OF RECYCLED AGGREGATE CONCRETE}

Concrete mixes (1.15: 2.3: 4.6) were formulated according to standard procedure (ASTM C192/C192 M) based on previous published results (Kamal et al., 2017). Demolition concrete was collected from Basrah city, all from the same place which was destroyed before a year. It was broken, crushed and sieved. The fraction matched with the standard size of coarse aggregate was separated and used in the concrete mixes. The cement, aggregates and water were blended; the obtained slurry was compacted in three layers in steel molds. The steel molds were cleaned and oiled properly prior to charging the concrete mix. After 24 hours the samples were de-molded then cured by placing in water at ambient temperature. The mix 
proportions of the concrete mix constituents for the 10 experiments were: $\mathrm{W} / \mathrm{C}=0.5,50 \%$ demolition aggregate from the whole content of natural coarse aggregate.

\section{EXPERIMENTAL DESIGN}

A 2-factorial central composite design of ten experiments (with $2 \times 2=4$ factorial points, $2 \times$ 2 star-points between the axis and 2 repetitions of central point), with the high and low values for factors being represented as 1 and -1 , and the middle value as 0 , was adopted to study the impact of concentration of the aggressive media ( $\mathrm{HAC} \& \mathrm{NaCl}$ ) solutions and the immersion period of the RAC specimens in the aggressive media. The analysis for each sample was replicated three times. The adopted design for the ten experiments is presented in Table 2.

Table 2. The Coded and actual levels of the operating parameters (independent variables) for the 10 experiments

\begin{tabular}{|l|l|l|l|l|l|}
\hline Coded level & $-\alpha$ & -1 & 0 & 1 & $+\alpha$ \\
\hline Concentration of aggressive media(Molar) & 0.10 & 0.15 & 0.28 & 0.40 & 0.45 \\
\hline Immersion Period (Day) & 0.57 & 1.50 & 3.75 & 6.00 & 6.93 \\
\hline
\end{tabular}

$\alpha$ is the axial distance

\begin{tabular}{|l|l|l|l|l|l|l|l|l|l|}
\hline Experiment number & 1 & 2 & $3,4^{*}$ & 5 & 6 & 7 & 8 & 9 & 10 \\
\hline Concentration of aggressive media(Molar) & 0.40 & 0.45 & 0.28 & 0.28 & 0.15 & 0.15 & 0.28 & 0.1 & 0.4 \\
\hline Immersion Period (Day) & 1.50 & 3.75 & 3.75 & 0.57 & 6.00 & 1.50 & 6.93 & 3.75 & 6.00 \\
\hline
\end{tabular}

*Repetitions of central points

\section{METHOD FOR CHEMICAL ATTACK}

The acid and salt resistance of the RAC was investigated using (Acid attack by HAC and salt attack by $\mathrm{NaCl}$ solutions). The test was carried out such as; the RACs specimens were removed from water after curing for 28 days, dehydrated, weighted and submerged in the aggressive solutions. After the submerging durations the specimens were removed from the solutions then dried. Weight loss, density and compressive strength were then measured. An average of three test results was considered. The weight loss (\%) was worked out using equation 2. 
Weight loss $(\%)=[$ Initial weight of the sample before immersion- Weight of sample after immersion/ Initial weight of the sample before immersion] $\times 100$

\section{MEASUREMENT OF DENSITY}

RACs cubes of age 28 days were dehydrated then weighted. The cubes volume was then precisely measured. The test was also carried out after immersion in the aggressive solutions. The density of recycled aggregate concrete was accounted as the average of three test results.

\subsection{Compression Strength Test}

A $150 \times 150 \times 150 \mathrm{~mm}$ concrete cube were prepared and tested by mechanical testing instrument model 50-C23C02 with load capacity $2000 \mathrm{kN}$. The load was applied on the cub specimen at a constant rate until the specimen broke down, and the corresponding load was recorded. The compressive strength of RACs specimens was accounted as the average three test results.

\section{RESULTS AND DISCUSSION}

\section{CHEMICAL ATTACK BY ACETIC ACID (HAC): EXPERIMENTAL DATA}

\section{ANALYSIS}

Concrete may be exposed to acid incursion by different inorganic acids. Organic acids including acetic and lactic may also attack concrete used for agricultural applications as the silage effluents containing mainly acetic acid. The unprotected concrete surfaces including animal houses, waste water treatment plants, sewer pipes and cooling towers when subjected to acetic acid are deteriorated seriously as a reason of formation of calcium acetate resulted from the reaction of cement hydration products with Acetic acid (Bertron et al., 2005) as shown in equations 3 and 4. 


$$
\begin{aligned}
& 2 \mathrm{CH}_{3} \mathrm{COOH}+\mathrm{Ca}(\mathrm{OH})_{2}=\mathrm{Ca}(\mathrm{CH} 3 \mathrm{COO})_{2}+2 \mathrm{H} 2 \mathrm{O} \\
& 2 \mathrm{CH}_{3} \mathrm{COOH}+\mathrm{C}-\mathrm{S}-\mathrm{H}=\mathrm{SiO}_{2}+\mathrm{Ca}(\mathrm{CH} 3 \mathrm{COO})_{2}+2 \mathrm{H} 2 \mathrm{O}
\end{aligned}
$$

The aggregate type, $\mathrm{pH}$, type of the acid and concrete composition are the major factors affect the chemical resistance of concrete exposed to acid attack (Yoon et al., 2016). In the current work, the chemical resistance test affirms that the RACs specimens lost some of their weight, compressive strength and density after immersion in HAC. The \% losses varied as a function of HAC concentration and immersion period of the specimens. Figure 1 shows histograms illustrated the variation of wt. \% loss (A); \% decrease in compressive strength (b); and \% decrease in density (C) in term of each experiment after HAC attack for the RACs samples.
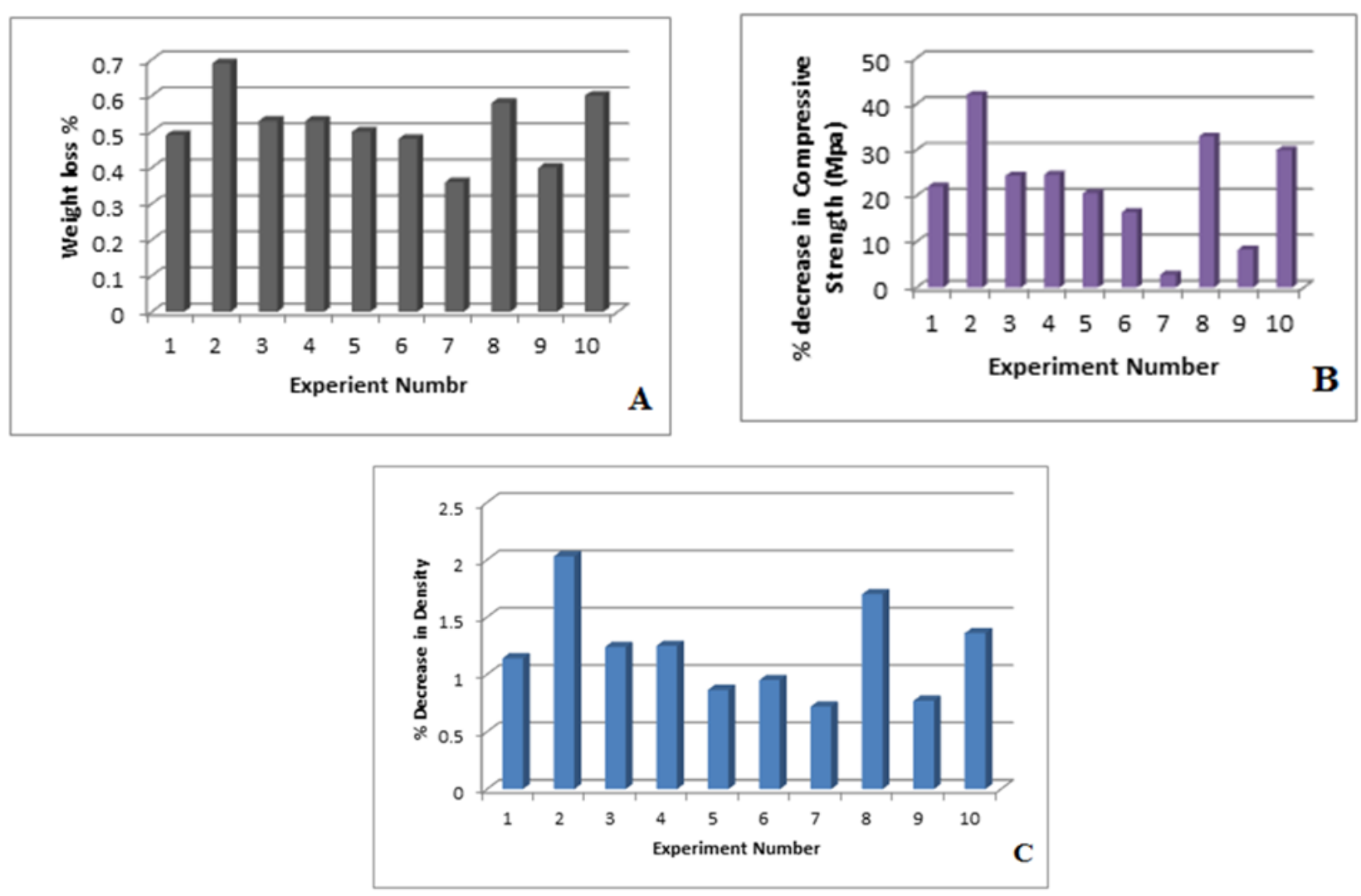

Figure 1. The variation of wt. \% loss (A); \% decrease in compressive strength (b); \% decrease in density (C) in term of each experiment after HAC attack for the RACs. 
It was reported that cement hydrates tend to lose calcium and decomposes to amorphous hydrogel when $\mathrm{pH}$ of the solution decreases to values lower than its stability limits. It was emphasized that the final products resulted from the reaction of acid with cement are ferric oxides, the acid calcium salt and the hydrogels of calcium and aluminum (Alexander et al., 2012, Izzat et al., 2013). Although Figure1 confirmed that the HAC strike resulted in decrease the wt. of the samples, density and compressive strength for all the 10 experiments. However, it is worthy to note that the specimens of high compressive strength before HAC attack were less deteriorated (of less weight loss) after the aggressive attack compared to those of lower compressive strength. Figure 2 shows the situation.

Mathematical correlations with high regression coefficient (0.8611) and (0.8889) were developed between $\%$ decrease in density with weight loss $\%$ and $\%$ decrease of compressive strength respectively. Figures 3 shows the positive phenomena govern the acid attack impact on RACs.

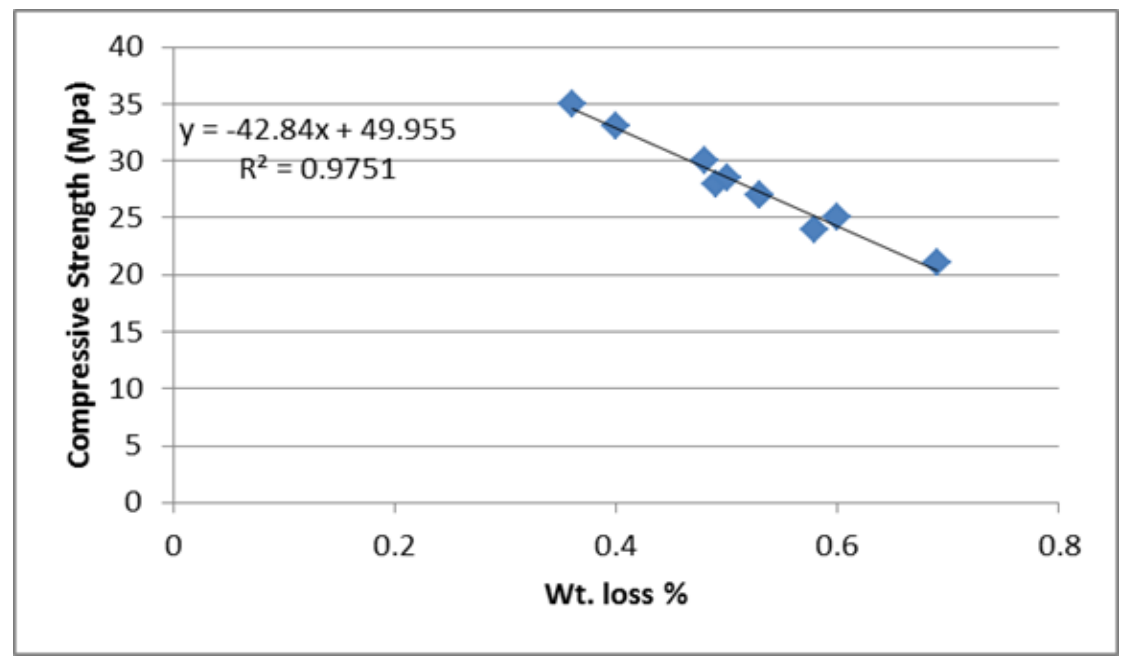

Figure 2 Variation of the initial compressive strength of RACs with wt. loss \%
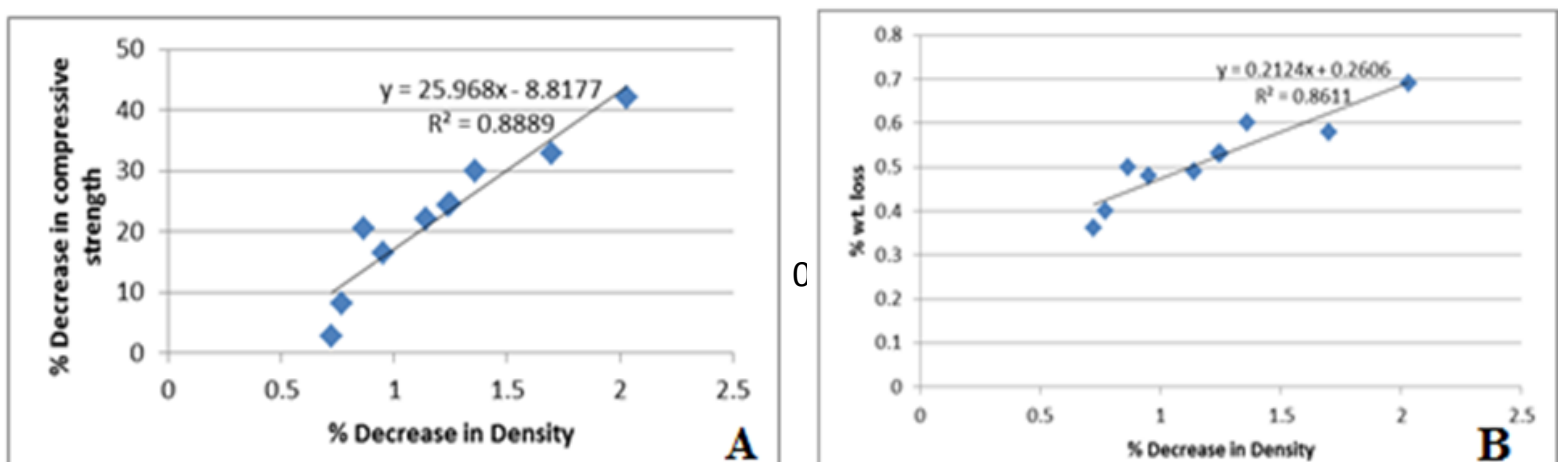
Figure 3. (A) \% decrease in compressive strength; (B) $\%$ weight loss versus $\%$ decrease in density for RACs specimens after immersion in HAC solution.

It has been indicated that the reason behind the increase in total porosity and average porosity diameter of RAC when the content of the Recycled aggregate (RA) increases is the porosity of RA owing to the fastening of old cement on its surface compared to natural coarse aggregate. Ntaryamira and his team demonstrated that the higher water absorption capacity and porosity and the lower density of the RA depend on the attached cement mortar content and quality (Ntaryamira et al., 2017). The aggressive solution attack of the hardened concrete leads to weakening the bonds between the concrete constituents then deterioration of concrete properties. The decrease in density of RACs after immersion in HAC is attributed to decreasing the concrete mass and increasing its volume because of absorption of the aggressive solutions that interact with concrete constituents resulted in swelling of concrete matrix.

\section{RSM ANALYSIS FOR HAC ATTACK}

While there are a number of papers in the literature concerning the attack of acids and salts on concrete utilized in civil construction, there has been less work reported on optimization and modeling the effect of the attack parameters on concrete properties. Response Surface

Methodology was employed for that purpose, and the results of RSM analysis are discussed in the next parts.

In various waste industries, it was observed that compressive strength and the durability of concrete structures are affected by the interactions of the hydrated cement phases with organic acids of short-chains (Snellings et al., 20120). The experimental data for compressive strength 
for RACs samples were studied using RSM. The RSM analysis findings are illustrated in Figure 4.

The response surface analysis of the developed model showed that concentration of HAC solution has significant effect on compressive strength, while no significance was observed for immersion period as shown in Pareto chart (a). However, compressive strength found to decline with augmentation the concentration of HAC and immersion duration of the samples as shown in the standardized effect plots (b). The 3D response surface of interactive effect between different HAC concentration and exposure time with wt. loss is illustrated in (C).

The high Regression Factor R-squared $=87.0567$ calculated by the response surface analysis of the experimental values reflects the adequate explanation of the experimental data by the developed model. The multinomial equation derived from the RSM analysis is displayed in equation 5 .

Compressive strength $=44.37-61.82 \mathrm{C}-1.83 \mathrm{~T}+47.60 \mathrm{C}^{2}+1.78 \mathrm{CT}+0.073 \mathrm{~T}^{2}$

Where, $\mathrm{C}$ is the concentration of HAC (Molar), $\mathrm{T}$ is the immersion time (Day). The optimum compressive strength equals $37.84 \mathrm{MPa}$ is estimated from the model for a RAC sample immersed for 0.56 day in $0.1 \mathrm{M}$ HAC.
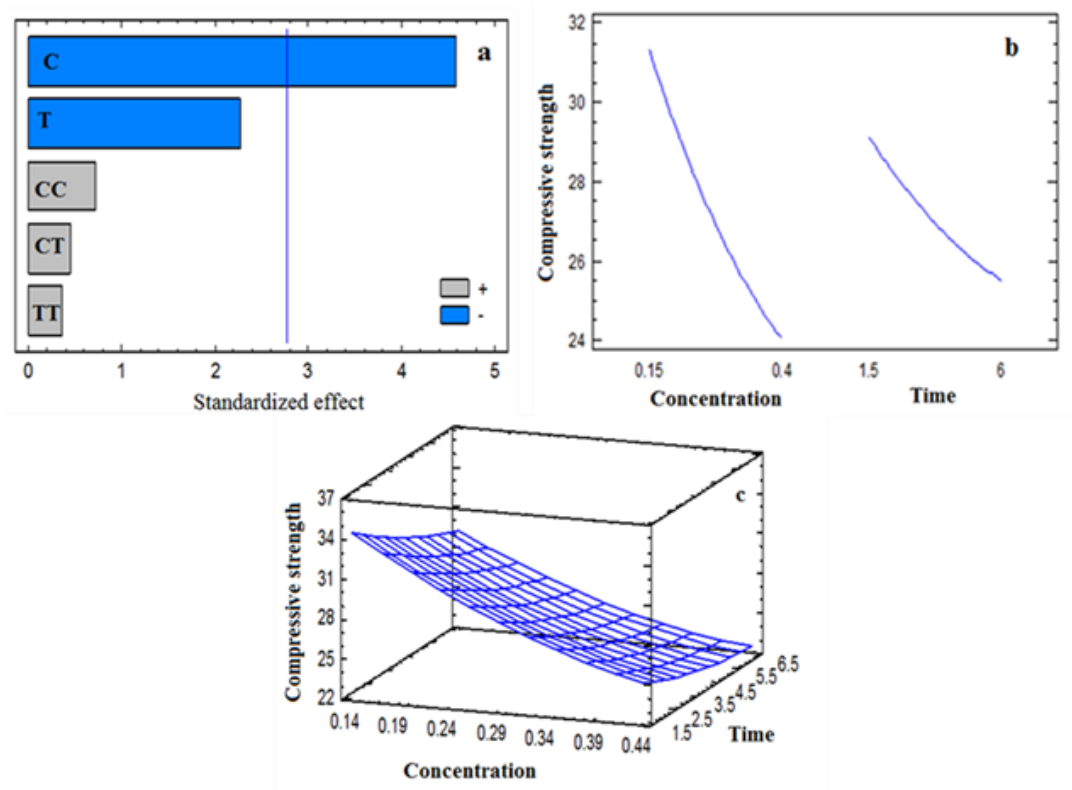
Figure 4. Pareto chart (a), Standardized effects (b), Estimated Response surfaces (c) for compressive strength of the RACs samples.
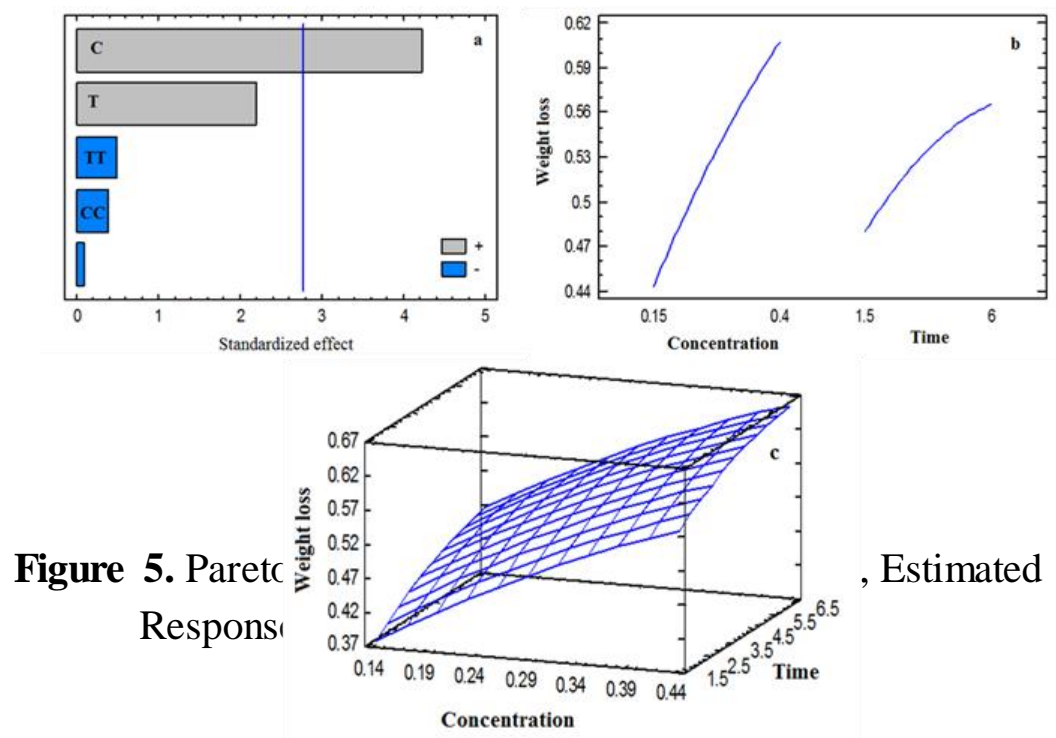

Similar trend was obtained for the effect of the operating variables on $\%$ wt. loss as shown in Figure 5.

The high Regression Factor R-squared $=85.2062$ derived from response surface analysis reflects the good fitting of the model. The multinomial equation extracted from the RSM analysis is set in equation 6 .

$$
\% \text { Weight loss }=0.19+1.05 \mathrm{C}+0.04 \mathrm{~T}-0.64 \mathrm{C}^{2}-0.009 \mathrm{C} \mathrm{T}-0.0025 \mathrm{~T}^{2}
$$

Where, $\mathrm{C}$ is the concentration of HAC (Molar), $\mathrm{T}$ is the immersion time (Day). 
The optimum \% weight loss (0.66) was estimated from the model for a RAC sample immersed for 6.96 day in 0.45 M HAC.

\section{CHEMICAL ATTACK BY NaCl: EXPERIMENT DATA ANALYSIS}

When cement containing materials expose to exterior chloride attack, the chloride ion may chemically tie up to the products formed from cement hydration, physically arrest to the surface of these products or subsist in the pore solution. Yuan and his co-workers reported that the factors affected the binding characteristics of cement containing materials include cement composition, the concentration of chloride, hydroxyl and sulfate ions, temperature, supplementary cementing materials, carbonation, the type of chloride salt cation, and application of electrical field (Yuan et al., 2009). In addition to the collapse of the inactive film on implant steel, the electrical resistivity of the concrete is affected by the content of chloride ions in concrete and, hence, the corrosion rate of steel (Pruckner and Gjorv, 2004). It was confirmed that chloride interference allowed the generation of Friedel's salt (Kim et al., 2016).

The chemical resistance test for RCAs after immersion in $\mathrm{NaCl}$ solutions assured that the RACs specimens lost some of their weigh, compressive strength and density after immersion in $\mathrm{NaCl}$. The losses varied as a function of $\mathrm{NaCl}$ concentration and immersion period of the specimens. The histograms show the situations in term of each experiment are illustrated in Figure 6.
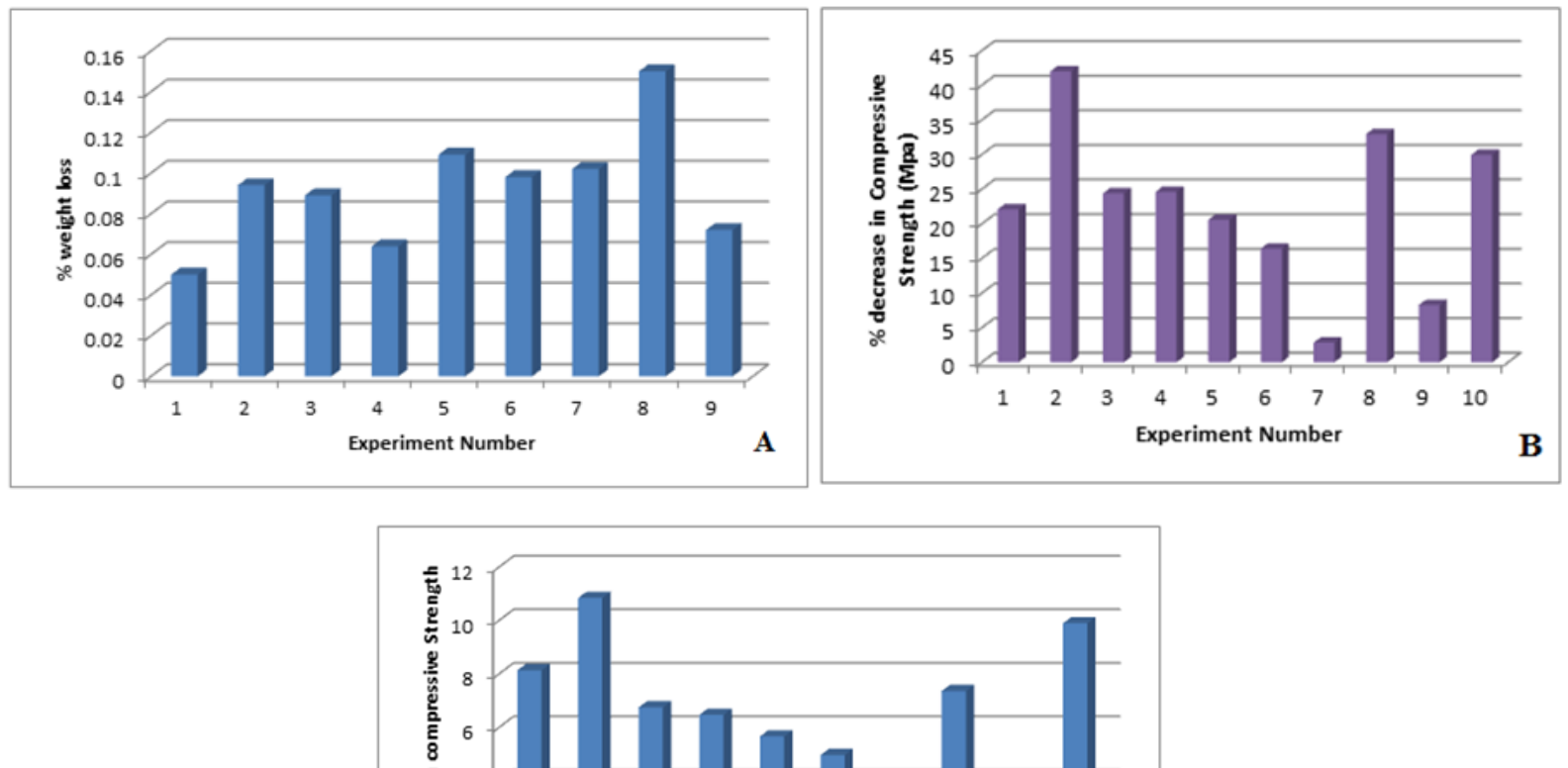
Figure 6. The variation of $\%$ decrease in wt. loss $\%(\mathrm{~A}) ; \%$ decrease in compressive strength (b); \% decrease in density $(\mathrm{C})$ in term of each experiment after $\mathrm{NaCl}$ attack for the RACs.

It is well noticed that the specimens of high compressive strength before $\mathrm{NaCl}$ attack were less deteriorated after the aggressive attack compared to those of lower compressive strength as visualized in Figure 7.

Positive correlations were developed between $\%$ decrease in density with $\%$ weight loss and $\%$ decrease of compressive strength. Figures 8 illustrate the corresponding plots and the adopted mathematical correlations.

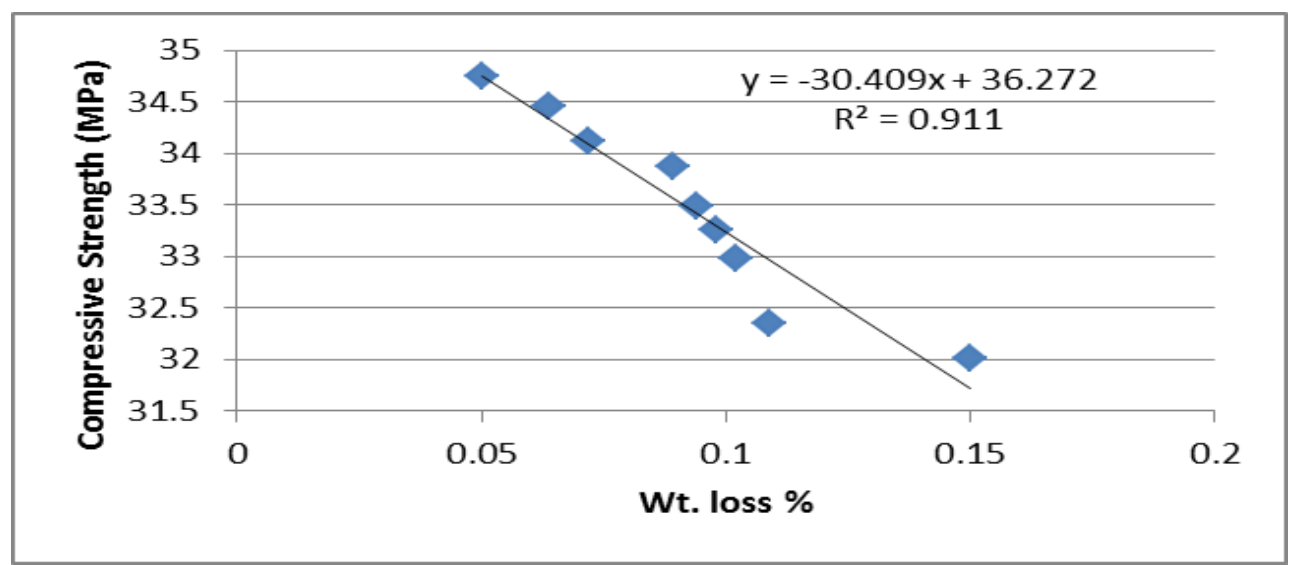

Figure 7. Compressive strength versus wt. loss \% (wt. loss is low when compressive strength before immersion is high).
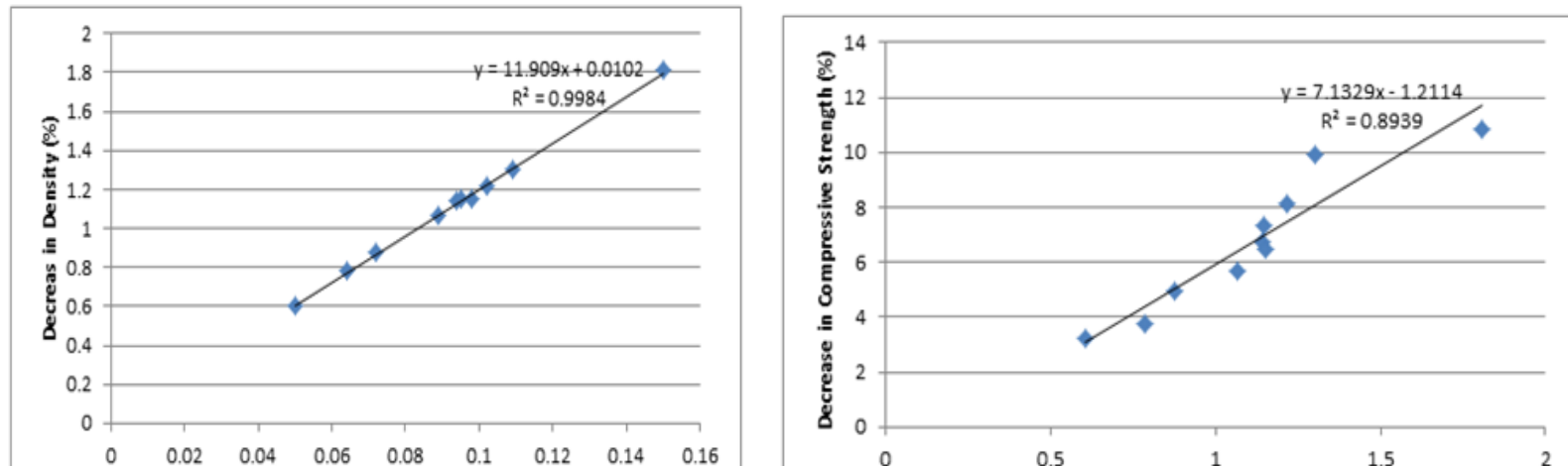
Figure 8. \% decrease in compressive strength (A); \% weight loss (B) versus $\%$ decrease in density for RACs specimens after immersion in $\mathrm{NaCl}$ solution.

\section{RSM ANALYSIS FOR NaCl ATTACK}

The RSM analysis of \% weight loss of RCAs samples attacked by $\mathrm{NaCl}$ solution showed that just the concentration of $\mathrm{NaCl}$ solution has significant effect on $\%$ weight loss of the specimens as set in [Figure 9: Pareto chart (a)]. However, \% weight loss increases sharply with increasing the concentration of $\mathrm{NaCl}$ and steeply with immersion duration of the samples as shown in the plots of the standardized effect (b). The three-dimensional (3D) response surface of interactive effect between varying $\mathrm{NaCl}$ concentration and exposure time with wt. loss is illustrated in (C).

As can be observed, the wt. loss elevates with the increments in the concentration of $\mathrm{NaCl}$ solution and immersion time.

The high Regression Factor R-squared $=88.8635$ taken from the report of response surface analysis of the experimental data reflects the good matching of the model with the practical results. The multinomial equation derived from the RSM analysis is manifested in equation 7.

$$
\% \text { Weight loss }=0.021+0.21 \mathrm{C}+0.006 \mathrm{~T}+0.016 \mathrm{C}^{2}-0.0009 \mathrm{CT}-0.0006 \mathrm{~T}^{2}
$$

Where, $\mathrm{C}$ is the concentration of $\mathrm{NaCl}$ (Molar), $\mathrm{T}$ is the immersion time (Day). 
The optimum \% weight loss was 0.13406 for a RAC sample immersed for 4.9 day in $0.45 \mathrm{M}$ $\mathrm{NaCl}$.

The results of RSM analysis of compressive strength of RCAs samples attacked by $\mathrm{NaCl}$ solution showed different trend. The RSA showed that both concentration of $\mathrm{NaCl}$ solution and immersion period has notable impact on compressive strength of the samples as visualized in Figure 10 Pareto chart (a). Compressive strengths decrease with increasing the concentration of $\mathrm{NaCl}$ and immersion duration of the samples in $\mathrm{NaCl}$ as show $\mathrm{n}$ in the plots of the standardized effect (b). While (C) shows the three-dimensional (3D) response surface of interactive effect between varying $\mathrm{NaCl}$ concentration and exposure time.
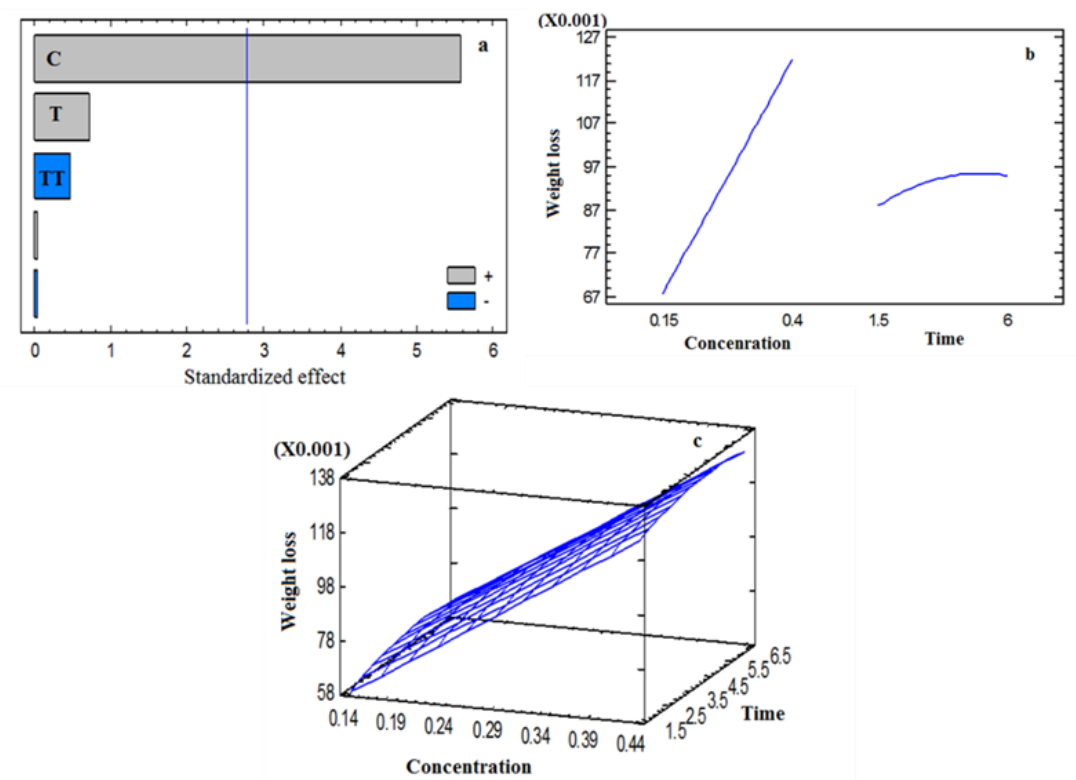

Figure 9 Pareto chart (a), Standardized effects (b), Response surfaces (c) for weight \% loss of the RACs samples for \% wt. loss after $\mathrm{NaCl}$ attack.

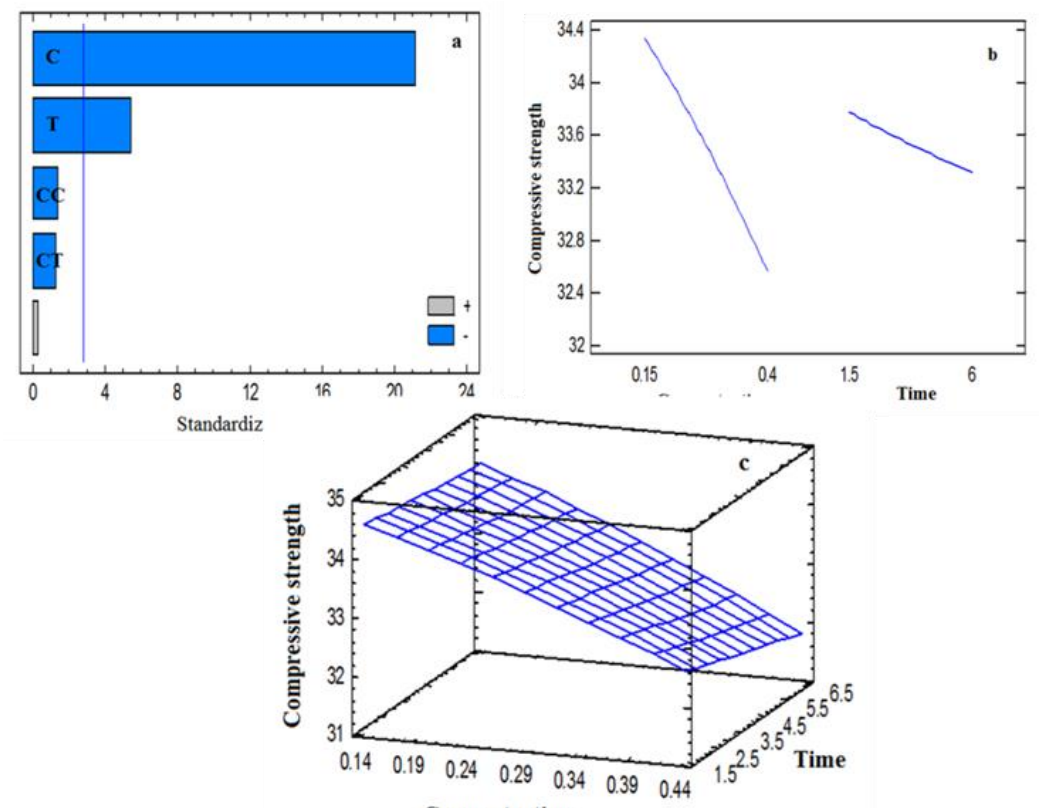


Figure 10 Pareto chart (a), Standardized effects (b), Response surfaces (c) for weight \% loss of the RACs samples for compressive strength after $\mathrm{NaCl}$ attack.

The very high Regression Factor $=99.175$ estimated from the RSA results reflects that the model has perfect fitting to the practical results. The multinomial equation in concern is put down in equation 8 :

$$
\text { Compressive strength }=35.28-3.5 \mathrm{C}-0.055 \mathrm{~T}-4.76 \mathrm{C}^{2}-0.27 \mathrm{CT}+0.0036 \mathrm{~T}^{2}
$$

Where, $\mathrm{C}$ is the concentration of $\mathrm{NaCl}$ (Molar), $\mathrm{T}$ is the immersion time (Day). The optimum compressive equals $34.8475 \mathrm{MPa}$ estimated from the model for a RCA sample immersed for 0.56 day in $0.1 \mathrm{M} \mathrm{NaCl}$.

Figure 11 shows a comparison between compressive strengths of RCAs samples after immersion in $\mathrm{HAC}$ and $\mathrm{NaCl}$ solutions. The figure reflects that the acid solution is more aggressive than the salt solution.

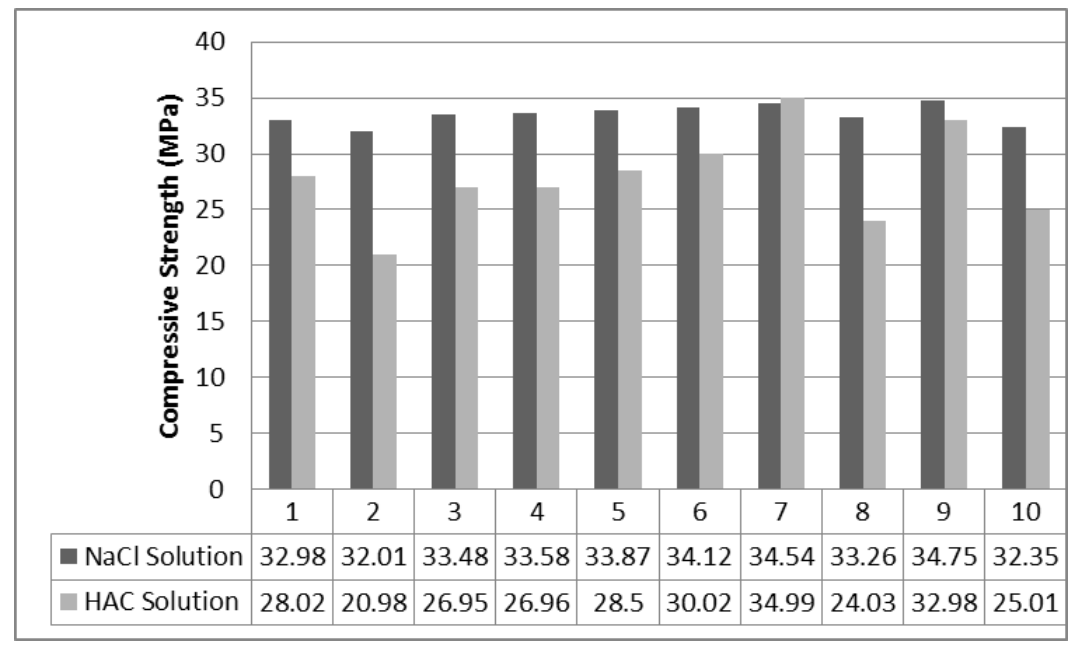

Figure 11 Average compressive strength after immersion in HAC and $\mathrm{NaCl}$ solutions. 
It is worthy to mention that physical and mechanical characteristics of RAC principally rely on the quality and content of the aggregates. Most of the findings found in the literature revealed that better, similar or lower characteristics could be obtained liken to natural aggregate concrete depending on the content and quality of the RA used (Yaprak et al., 2011; Salehlamein et al., 2015; Kanget al., 2018). Investigation of the long-period properties of RAC exposed to aggressive media (for example 90 days or more) is not a theme in the current work. However, it may be a task of a future work. Nevertheless, it is well established that increasing the content of the recycled aggregate and the exposure duration of the attacked chemicals resulted in a negative impact on concrete durability (Loren et al., 2020).

\section{CONCLUSIONS}

The present work sorted out the following conclusions:

1. Both Acetic acid (HAC) and $(\mathrm{NaCl})$ solutions are vulnerable to attack concrete contain demolition recycled coarse aggregate.

2. The solutions cause deterioration in compressive strength and density, as well as result in increasing in weight loss.

3. The magnitude of depression in concrete properties relies on concentration of the aggressive media and the immersion duration of concrete samples. Increasing the concentration of the aggressive solutions and immersion period leading to depression of compressive strength and density as well as increasing the concrete samples weight loss.

4. The impact of exposing the RACs to the acid (HAC) solution is more effective and harsher than the salt $(\mathrm{NaCl})$ solution. 
5. The depression in RACs properties after immersion in the aggressive media may be attributed to quality and content of the cement mortar fastened to recycled aggregate's granules as well as to the physical characteristics of the grains.

6. RSM is an effective tool to study the effect of more than one variable at the same time, and investigating the interaction between the studied variable. Using of such statistical analysis software resulted in decreasing the number of experiments, chemicals used and practical efforts, in addition to give the opportunity to estimation the mathematical models expressing the impact of the operating variables on concrete properties as well as optimization the investigated properties.

\section{REFERENCES}

Nochaiya, T., Wongkeo, W., Chaipanich A. 2010. Utilization of fly ash with silica fume and properties of Portland cement-fly ash-silica fume concrete. Fuel 89: 768-774.

Malesev, M., Radonjanin, V., Broceta. G. 2014. Properties of recycled aggregate concrete. Contemporary Materials 2: 239 - 249.

Ghaffar, S.H., Burman, M., Braimah, N. 2020. Pathways to circular construction: An integrated management of construction and demolition waste for resource recovery. Journal of Cleaner Production 244: 118710.

Omotayo, O.O, Akingbonmire, S.L., Ikumapayi, C.M. 2019. Sustainable application of materials from construction and demolition waste: A review. J of Engineering and Engineering technology 13(2): 228-242.

Shi, X., Fay, L., Peterson, M. M., Berry, M., \&. Mooney, M. 2011. FESEM/EDX investigation into how continuous deicer exposure affects the chemistry of Portland cement concrete. Construction and building materials 25 (2):957-966. 
Kamal, I., Sherwani, A. F, Ali, A., Falih S., Hassan S. 2017. Demolition Aggregate Concrete: Modeling and Optimization of Some Short-Term Properties. International Journal of Engineering Sciences \& Research Technology 6: 90-105.

Li Y., Zhou H., Su L., Hou H., and Dang L. 2017. Investigation into the Application of Construction and Demolition Waste in Urban Roads. Advances in Material Science and Engineering, $\quad$ Volume $\quad$ 2017, $\quad$ Article $\quad$ ID 9510212. https://www.hindawi.com/journals/amse/2017/9510212/

Rodríguez, G., Sáez del Bosque, I.F., Asensio, E. 2020. Construction and demolition waste applications and maximum daily output in Spanish recycling plants. Waste Management \& Research 38(4):423-432.

Poulsen, E., Mejlbro, L. Diffusion of Chloride in Concrete-Theory and Application, $1^{\text {st }}$ edition, Taylor \& Francis; London, CRC Press, 2005.

Tang, L. Chloride Transport in Concrete- measurement and prediction", doctoral thesis, Chalmers University of Technology, Gotenborg, 1996.

Neville, A. M. Properties of Concrete, Pearson Education, 2011.

Varghese P.C. Building materials, PHI Learning, New Delhi, 2010.

Liang, M., Huang R., Fang, S. 2013. Carbonation service life prediction of existing concrete viaduct/bridge using time-dependent reliability analysis, Journal of Marine Science and Technology 21(1): 2194-104.

Shi, C., Mo, Y. L. High-Performance Construction Materials Sciences and Applications, World Scientific Publishing Co. Pte. Ltd, Singapore., 2008.

Attiogbe, E. K., Rizkalla S. H. 1988. Response of Concrete to Sulfuric Acid Attack, ACI Materials Journal 85(6):481-488. 
Alcatraz, G. \& Goridis, C. 1991. Biosynthesis and processing of polysialylated NCAM by AtT-20 cells. European Journal of Cell Biology 55(1): 165-73.

Eckhardt, M. Muhlenhoff, M., Bethe, A., Koopman, J., Frosch, M., \& Gerardy-Schahn, R. 1995. Molecular characterization of eukaryotic polysialyltransferase-1. Nature 373(6516): $715-8$.

Wu, K., Han, H., Xu, L., Yang, S., and De Schutter, G . 2019. Supported ITZ Modification Efficiencies via Surface Coating Nanoparticles on Aggregate and its Influence on Properties. Materials 12(21); 3541.

Brendt, N. L. 2001. Protection of concrete in cooling towers from microbiologically influenced corrosion. Geothermal resources council transactions 25:3-257.

Bertron, A., Escadeillas, G., Duchesne J. 2004. Cement pastes alteration by liquid manure organic acids: chemical and mineralogical characterization. Cement Concrete Res. 34:182335 .

Bertron, A., Duchesne, J., Escadeillas, G. 2005. Attack of cement pastes exposed to organic acids in manure". Cement \& Concrete Composites 27: 898-909.

Mehta, P.K., Monteiro, P.J.M. Concrete: Microstructure, Properties, and Materials;" McGraw-Hill: New York, USA, 2006.

Hirao, H., Yamada, K., Takahashi, H., Zibara H. (2005). Chloride binding of cement estimated by binding isotherms of hydrates. J. Adv. Concr. Technol. 3: 77-84.

Dembovskaa, L., Bajarea, D., Pundieneb, I., Vitolaa, L. (2017). Effect of Pozzolanic Additives on the Strength Development of High-Performance Concrete. Procedia Engineering 172: $202-210$.

Iraqi specification IQ.S. No 5, "Portland cement", Central Organization for Standardization and Quality Control, 1984. 
Iraqi specification IQ.S. No 45, "Natural aggregate used in concrete", Central Organization for Standardization and Quality Control, 1980.

Yoon, S., Ha, J., Chae, S. R., Kilcoyne, D.A, Oh, J.E. and Monteiro, P.J.M 2016. Phase Changes of monosulfoaluminate in $\mathrm{NaCl}$ Aqueous Solution. Materials (Basel) 9: 401.

Cihan, M.T., Guner, A., Yuzer, N. (2013). Response surfaces for compressive strength of concrete. Construction and Building Materials 40: 763-774.

Revathi, T., Jeyalakshmi, R., Rajamane, N.P., Baskarasundararaj, J. 2018. Application of Response Surface Methodology: Optimum Mix Design of Fly ash geopolymer mortar, a Portland cement free binder for sustainable construction. International Journal of ChemTech Research 11: 13-22.

ASTM C192/C192 M, "Standard Practices for Making and Curing Concrete Test Specimens in the Laboratory", The American Society for Testing and Materials, Philadelphia, 2004.

Alexander, M., Bertron, A., De Belie, N. 2012. Performance of Cement-Based Materials in Aggressive Aqueous Environments: State-of-the-Art Report, RILEM TC 211 - PAE, Springer Science \& Business Media.

Izzat, A. M., Al Bakri, A.M.M., Kamarudin, H., Sandu, A.V., Ruzaidi, G.C.M., Faheem, M.T.M., Moga, L.M. 2013. Sulfuric Acid Attack on Ordinary Portland Cement and Geopolymer Material. REV. CHIM. (Bucharest) 64 (9):1011-1014.

Ntaryamira T., Quansah A., Zhang Y. 2017. Assessment of recycled concrete aggregate (RCA) usage in concrete. International Journal of Research in Engineering and Technology 6 (120):72-78.

Snellings, R., Mertens, G., Elsen J. 2012. Supplementary cementitious materials. Reviews in Mineralogy and Geochemistry 74: 211-278. 
Yuan, Q., Shi, C., De Schutter, G., Deng, D. 2009. Chloride Binding of Cement-Based Materials Subjected to External Chloride Environment - A Review. Construction and Building Materials 23(1): 1-13.

Pruckner, F., Gjorv ,O.E. 2004. Effect of $\mathrm{CaCl} 2$ and $\mathrm{NaCl}$ additions on concrete corrosivity. Cement and Concrete Research, 34(7):1209-1217.

Kim, M. J., Kim, K.B., and Ann, K.Y. 2016. The Influence of C3A Content in Cement on the Chloride Transport. Volume 2016, Article ID 5962821 https://www.hindawi.com/journals/amse/2016/5962821/

Yaprak, H., Aruntaş, H. Y., Demir, I., Simsek, O, Durmuş G. 2011. Effects of the fine recycled concrete aggregates on the concrete properties. International journal of physical sciences 6: 2455-2461.

Salehlamein, F. R., Solikin, M., Sunarjono I. 2015. Effect of Recycled Coarse Aggregate on Concrete Properties. International Journal of Innovative Research in Science, Engineering and Technology 4:19060-19068.

Kang, M. and Weibin L. 2018. Effect of the Aggregate Size on Strength Properties of Recycled Aggregate Concrete. Advances in Materials Science and Engineering Volume 2018, Article ID 2428576. https://www.hindawi.com/journals/amse/2018/2428576/

Loren, L P., Rombi, F.J., Mistretta, F., Sassu, M. and Stochino F. 2020. Effect of Parent Concrete on the Performance of Recycled Aggregate Concrete. Sustainability 12: 9399. 